\title{
38 THE IMPACT OF SOCIO ECONOMIC FACTORS ON INJURIES IN TEHRAN, IR IRAN
}

doi:10.1136/injuryprev-2012-040590w.38

${ }^{1}$ AR Moghisi, ${ }^{2}$ A Farshad. ${ }^{1}$ Public Health Science department, KI, Stockholm; ${ }^{2}$ Tehran University of Medical Science, Iran

Introduction Tehran is the capital city of IR Iran with about 12000000 inhabitants. Consisting of 22 districts. Injuries happen with different rate and type in different zones.

Objectives To improve urban management in terms of injury prevention.

Methodology $10 \%$ of population on of Tehran was considered for the households' survey. A questioner based on Urban HEART (urban Health Equity Assessment and Response Tool) was prepared and validated. Interviewers were trained uniformly. SPSS soft ware was used to analysing data.

Result Females were mostly involved in fall, burn and poisoning while men were mostly involved in traffic related accidents, interpersonal violence and electric shocks. Most accidents were among families with 3-5 members. Young's adult aging 15-40-years-old and living in the low income districts of Tehran were the most affected by accidents? Young males who are the residence of districts $14,15,18,9,19$ and 4 are the most affecting victims by traffic related accidents. In district 11, 12, 14 most of the victims were motorcyclists. In districts 2,3 and 5 victims were shifted towards pedestrians predominantly. Children and old ages are mostly the victims of fall related accidents; there was no gender differences detected in most of the districts area except in district 19 where males were falling twice than females, in districts $1,2,3$ and 12 this ratio was vice versa $(p<0.05)$. Burns related accidents were recorded more in districts $13,16,17,12$ and the least from districts 3, 2, and 5 respectively $(p<0.05,95 \% \mathrm{CI})$.

Significance to the Field The result of this study will be used as a baseline data for interventions assessment in future. 